\title{
An Investigation of the Rice Processing Village Programme
}

\author{
C.A.K. Dissanayake ${ }^{*}$ S. De Silva ${ }^{1}$, W.M.C.B. Wasala ${ }^{2}$ and B.M.K.S. Thilakarathne ${ }^{2}$
}

\author{
Postgraduate Institute of Agriculture \\ University of Peradeniya
}

Sri Lanka

\begin{abstract}
The Rice Processing Village programme (RPV) was introduced by the Institute of Post Harvest Technology in which farmers produce and sell value added products instead of paddy. It is an income generating and livelihood development programme that provides economic benefits for the rural people. The paper aims to determine the success of the RPV programme in the formation of five capital resources: physical, financial, human, social and natural. Fifty members from six RPVs in Anuradhapura district were randomly selected for the survey. Data were collected through a field survey using a questionnaire, key informant interviews and secondary data sources. The study revealed that the members have developed the human, social, physical and financial resources and used the natural capital effectively to generate an average additional monthly income of Rs.17, 530 per family. Therefore, RPV is an economically beneficial and socially acceptable livelihood development programme for rice producing rural communities in Anuradhapura district.
\end{abstract}

Keywords: capital sources, income generation, livelihood development, rice processing village, rural community

\section{INTRODUCTION}

Sri Lanka being based on an agricultural economy, the agricultural contribution to the GDP was $11.2 \%$ in 2011 (Central Bank, 2012). According to the Department of Census and Statistics (2012), in Sri Lanka, the majority (80\%) of the population live in the rural areas and about one-third (33\%) of them are employed in the agricultural sector (Central Bank, 2012). According to the World Bank (2012), the poverty head count ratio at national poverty line is $8.9 \%$ and the country is graded as a lower middle income nation.

Paddy is the major agricultural crop cultivated in Sri Lanka. In 2011, paddy production was 3.875 million metric tons (Central Bank, 2012). Paddy farming is a direct source of income for the farmers as well as an indirect source of income for the providers of support services, paddy millers and traders of paddy and rice (Kumara et al., 2008). However, due to high cost of production, lower prices at the harvesting season and debts to be paid just after harvesting have caused many financial difficulties especially to small-scale paddy farmers in Sri Lanka. Farmers are used to sell their unprocessed paddy to middlemen and/or millers. In between the paddy farmer and the consumer, there are many middlemen involved, resulting in a longer supply chain; thus the share of the consumers rupees that goes to the farmer declines.

Department of Agricultural Extension, Faculty of Agriculture, University of Peradeniya, Peradeniya, Sri Lanka Institute of Post Harvest Technology, Jayanthi Mawatha, Anuradhapura

Author for correspondence : chamdissanayake@yahoo.com 
By shortening the supply chain, consumers can purchase rice at a reasonable price while providing sufficient return to the producers (Gamawelagedara et al., 2010).

In order to address this issue, the Institute of Post Harvest Technology (IPHT) introduced the rural level rice parboiling and processing enterprises to the communities through the Rice Processing Village (RPV) programme. This programme was launched as a pilot development project by the Institute in Anuradhapura district in 2005 and it proved to be a successful programme. Thereafter, it was scaled up towards the other major paddy cultivating districts in the country including Polonnaruwa, Kurunegala, Ampara, Kandy and Puttlam. The RPV programme attempts to increase the income level of the paddy farmers through facilitating selling rice instead of paddy, initiation of agro-based self-employment opportunities at rural level (parboiling and processing), development of small/medium scale rice mills to produce high quality rice at rural level and make high quality rice available at a lower price to the consumers (Institute of Post Harvest Technology, 2006).

A RPV consists of 10 to 20 farm families grouped into a community based organization called Rice Processors' Association. It comprises of paddy farmers, rice processing families, and rice millers involved in producing, parboiling, milling and trading. At present there are about 4,000 farm families involved in 289 RPVs. In addition to providing technology and training, IPHT's services include facilitating organizational change processes and building linkages among different value chain actors and other back-up service providers (Fig 1).

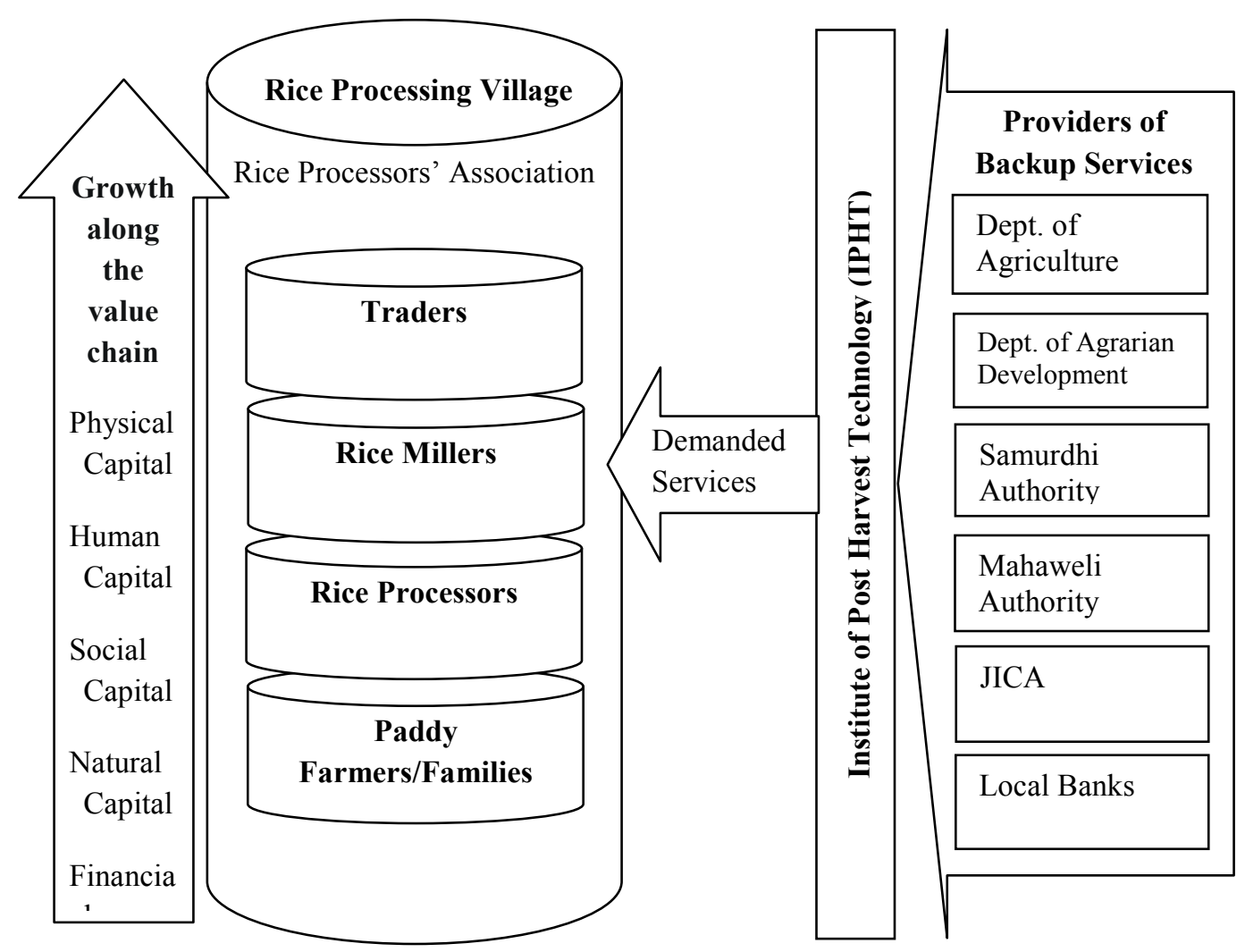

Fig. 1. A value chain approach to RPV development 
According to Curtaran (2008), the resources that help people to survive and thrive are the capital assets. Goodwin (2003) had stated that "for something to be considered a capital asset, it must have the potential to produce something that is economically desirable". Insufficient and lack of access to capital is a major cause of failure of many small businesses including farming. Adequate capital is needed to start up the business, operate through hard times, and provide a good chance to become a profitable enterprise (McConnon, 2008). According to Kleih (2009), there are five capital resources, namely human, social, physical, natural and financial. Human capital includes resources such as skills, knowledge, ability to work and good health. Social capital is determined by relationships and networks, which exist within families, among and between communities, groups and institutions. Social relations further influence the way in which people access and make better use of assets. The quality and quantity of natural resources available for the people will provide them with different livelihood options. Physical capital includes the basic infrastructure such as transport, shelter, sanitation, water, energy and communications as well as the production equipment that enable people to pursue their livelihoods. These capital sources must be put together and used properly to achieve the goals sustainably. This paper attempts to evaluate the effectiveness of the RPV programme in generating employment and income of rural communities in Anuradhapura district through the development of five capital sources.

\section{METHODOLOGY}

This programme was first launched in Anuradhapura district in 2005. Six RPVs were randomly selected from the villages having a minimum of 4 year period operation after establishment. They were located in three Divisional Secretariat Divisions namely, Rajanganaya, Nochchiyagama and Nuwara Gam Palatha-central. Out of the total 76 members in these six villages, 60 members ( 10 members from each village) were randomly selected. However, there were only 50 usable filled questionnaires resulting an $83 \%$ response rate. Both quantitative and qualitative data were gathered regarding the general information, acquisition and development of capital sources (physical, human, social, financial and natural), income generated, cost of production and related information through a field survey using a pre-tested semi-structured questionnaire. Furthermore, data were collected through key informant interviews with Agricultural Instructors of the Department of Agriculture, Agriculture Research and Production Assistants, relevant officers of the IPHT and organization involved in funding these RPVs namely, the Pro-Poor Economic Advancement and Community Enhancement Project (PEACE) implemented by the Ministry of Irrigation. The presidents of the Rice Processors' Associations in each village were separately interviewed using a check list. Additional information was collected from direct field observations and also from secondary sources such as research and other reports of the IPHT. Data were analyzed using the SPSS software.

\section{RESULTS AND DISCUSSION}

According to the IPHT, these six villages had been selected for establishment of RPVs on the recommendation of the North Central Provincial and Inter-Provincial Departments of Agriculture. The basic selection criteria included the major crop cultivated in the village being paddy, and the farmers generate a relatively low income from paddy farming. Subsequently awareness was created among the villagers to make them interested on RPV programme and it was followed by a complete awareness and a training programme conducted in the village by the IPHT. The training programme had been on high quality rice 
processing at rural level (Details are discussed under human capital development section). About 130 villagers had participated in these training programmes in the respective villages. After the training programme, the participants who were willing to participate in this rice processing activities had been organized as a group, which was later developed into a Rice Processors' Association (RPA), in each village. Out of these trained beneficiaries, the majority (88\%) acquired membership in the RPAs. Among the members of this association, there were members engaged in different activities such as paddy parboiling $(96 \%)$, paddy supplying (2\%) and rice milling (8\%). With time, out of the initial 114 members $40(35 \%)$ dropped out of the RPA, due to various reasons including health and family problems. By the end of 2011, 76 members were involved in the six RPAs. The majority (59\%) of the initial members continued to be engaged in the rice processing activities. The following section discusses the ways and means of formation and utilization of the five capital sources in these RPVs for the benefit of the rural communities.

\section{a). Physical capital}

Physical capital in this programme can be divided into two categories such as raw materials and other supporting infrastructure, machinery and equipment. Paddy is the basic raw material required for this business. Out of the sample, the majority $(90 \%)$ of the beneficiaries were paddy farmers. Out of the rest, two had started cultivating paddy after joining this programme. Being situated in the major paddy cultivating area of the district, these six villages have easy access to paddy if they are to expand the business.

The infrastructure facilities required for this business were paddy store, soaking tank or utensils, parboiling vessels, unloading devices like shovel, plates or buckets, drying yards/carpets and milling machinery. The respondents used the available resources and also developed or purchased the required facilities. After joining the programme, $22 \%$ of respondents had increased their capacity for paddy storage, $78 \%$ had built cement soaking tanks, while $58 \%$ developed cement drying yards and $98 \%$ purchased parboiling vessels from IPHT. All these villages had access to three-phase electricity enabling them to run smallscale rice mills.

\section{b). Human capital}

The human capabilities depend not only on the knowledge, skills, attitudes, and aspirations; they also include useful behavioural habits as well as one's energy, physical and mental health. All these aspects of human capital have some component of inherited characteristics, but they must also be created and enhanced through nurturance, education, training and other aspects of life experience (Goodwin, 2003).

All the respondents reported that before starting this rice processing activities, husbands were the sole bread winner of the family. Women were mainly involved in household chores and supported their husbands in the field work. They were hardly involved in any income generation activity. Paddy, being cultivated in two seasons, provided paddy farming families adequate free time to get involved effectively in another income generating activity. The rice processing activity involves strenuous activities such as lifting paddy bags, cleaning, parboiling and unloading. All the respondents claimed that they used $100 \%$ family labour. Parboiling in these RPVs was mostly done by women, who had been involved in this activity traditionally. Therefore, the participants had traditional knowledge and experience and favourable attitudes towards parboiling. 
Training on theoretical and practical aspects mainly through demonstrations were conducted by the IPHT on cottage level high quality rice processing. The IPHT training programmes included topics such as problem analysis of selling unprocessed paddy and earning a lower income, cost benefit analysis of selling value added products like rice instead of paddy, technology involved in producing high quality rice at the rural level starting from harvesting to packing of processed rice, marketing, business management, recording and book keeping. Improved paddy parboiling methods ${ }^{3}$ were introduced to the farmers. Special market oriented training was given to two selected members from each group. Market oriented advisory services including understanding markets, business planning, record keeping, improving production, as well as advice on legal, regulatory and certification issues were continuously provided to the members. Know-how to enable value chain actors to meet market or value chain quality requirements (e.g. post-harvest handling and storage, product value addition, processing and packaging technology, meeting food safety and agricultural practices standards, consumer rights) were also provided. These trained members served as trainers to their fellow members and monitoring officers of the RPV. The IPHT also facilitated and stimulated changes in value chain management including coordination of production and establishment of collective marketing, negotiation of contracts, legal aspects, brand development and linking producers to the supply chains.

Supervision and follow up visits are carried out to ensure high quality rice production and proper implementation of the project after commencement of rice parboiling and processing activities. Cross-learning is also taking place as competencies on rice processing are transferred to the other villagers in an informal way and there were 12 such farmers who had started their own business after learning the processing technique due to the cross- learning activity. All the respondents reported that their knowledge, skills and attitudes were improved with the training and support given by IPHT and other supporting institutions. These improvements had yielded a favourable and stable behavioural change, as indicated by a large majority (88\%) adopting the new technology.

Of the total number of members in these six associations, the majority (76\%) were females. Out of the male members, only one-fourth were engaged in the rice processing activities by themselves, while in the other families the wives conducted most of the rice processing activities. In the six RPVs, most (87\%) of the RPA office bearers were women. Therefore, this programme had a very favourable effect on the women empowerment.

\section{c). Social capital}

According to Goodwin (2003), social capital refers to the characteristics of a society that encourage cooperation among groups of people, whose joint interdependent efforts are needed to achieve a common goal such as efficient production. The IPHT facilitated linkages among different actors along the value chains (e.g. convening multi-stakeholder forums to understand market trends and drivers, to foster better mutual understanding and trust, to identify bottlenecks along the value chains and to devise solutions). In each RPV a Rice Processors' Association was established as a Community Based Organization where farmers themselves had the ownership of the association as well as the programme. They were united into one cohesive group where social capital was enhanced.

\footnotetext{
${ }^{3}$ This improved method had overcome the drawbacks of conventional parboiling such as partial parboiling which results in a product with white bellies and poor milling qualities and appearance.
} 
Social capital had been used in activities such as procurement, processing, transporting, marketing and branding, and other social activities of the association. This social capital had facilitated the entrepreneurs to gain other capital assets as well. All the respondents (100\%) reported that this group approach had benefited them in obtaining credit and making contacts with other organizations.

\section{d). Natural capital}

The RPVs were located in paddy cultivating rural areas in the dry zone of Sri Lanka. The raw material was either produced by the farmers themselves or easily accessed from neighbouring producers. All the members used natural sunlight to dry the parboiled paddy. Paddy drying was facilitated by sunny dry weather, which exists during most part of the year. The majority $(90 \%)$ of the participants used well water and the rest were using pipe-borne water. Firewood, coconut husk and paddy husk were used as fuel for the stove to parboil. These were easily accessed either from their home gardens or their own mill. This local availability and use of natural resources in the income generation activities had lowered the cost of production while giving a higher profit margin.

\section{e). Financial capital}

The improvement of financial capital of the village could be mainly seen by the subsidies given to the members, access to formal credit and establishment of the rural financing system through the Rice Processors' Association. The IPHT provided steam parboiling equipment which is the main processing equipment used in these villages. Out of the respondents, some at the initial stage $(28 \%)$ received these equipment at $50 \%$ to $100 \%$ subsidized rates. The majority $(72 \%)$ had received subsidies from JICA's PEACE project, Department of Agriculture (DOA), IPHT and political bodies for various activities related to the RPV programme including purchasing parboiling equipment, milling machinery, and improving drying and storage facilities.

Of the respondents, $100 \%$ at inception stage and $66 \%$ at present indicated that financial inadequacy was their main problem to start and develop this programme into a large scale enterprise. To overcome this problem the IPHT had intervened and established a link with Regional Development Bank, Anuradhapura so that farmers and processors could access to credit at low interest rate, and faster. Members had used these funds to purchase necessary equipment to parboil and dry paddy and or repay the loans obtained and keep a stock of paddy for processing.

The study revealed that the majority (78\%) had borrowed credit from local banks, mainly from the Regional Development Bank, for purchasing paddy and equipment, development or construction of necessary facilities required for this income generating activity. Information on credit obtained is given in Table 1 . The total credit obtained by all the respondents amounted to Rs. 4,590,000.00 from 2005 to 2012. None of them became defaulters and had no problems of repayment. 
Table 1. Description of credit usage in the RPVs

\begin{tabular}{lrrr}
\hline Indicator & Average & Maximum & \multicolumn{1}{c}{ Range } \\
\hline Total credit taken (period 7 years) Rs. & 135,000 & $1,150,000$ & 30,000 to $1,150,000$ \\
Credit per each borrowing Rs. & 64,750 & 500,000 & 30,000 to 500,000 \\
Number of times borrowed & 2 & 6 & 0 to 6 \\
\hline
\end{tabular}

\section{Socio-economic impacts of RPVs}

Under this RPV, parboiled rice is produced at cottage level having good consumer preference characteristics such as good colour, without bad odour, less black grains and broken rice, de-stoned and with high quality. Since processing is undertaken by the farmer families, and due to the simplicity of the technology, the production cost is low. The technology was simple and could be learnt and used by anyone in a short time. Thus quality rice could be continuously supplied to the market at a low price by the members of the RPV instead of selling unprocessed paddy.

The major rice selling methods in these RPVs were rice sold in loose and packed form at home, weekly fairs, offices, retail shops and wholesale shops. In the studied RPVs, each rice processing family were supplying rice ranging from $300 \mathrm{~kg}$ to $5000 \mathrm{~kg}$ per month to the market.

This programme had led to rural level employment generation resulting in better living conditions and higher satisfaction not only among the employees but also within the family, a necessary condition for sustainable development. The average profit gained from this rice processing business ranged from Rs. 3500 to Rs. 50,000 per month and the mean income generated from this programme was Rs.17,530.00 per month. This has proven to be a very successful income generation activity at the rural level (Table 2).

Table 2. Economic benefits of rice processing

\begin{tabular}{lr}
\hline Description & Amount (Rs.) \\
\hline Cost of processing for kilogram of rice & \\
a) Paddy (Price of 1kg paddy @ Rs. 30.00; and Rice yield 68\%) & 44.50 \\
b) Parboiling and milling & 4.50 \\
c) Packaging & 1.00 \\
Total cost (a+b+c) & 50.00 \\
Sales revenue from kilogram of rice & 60.00 \\
Profit margin per kilogram of rice & 10.00 \\
\hline
\end{tabular}

\section{CONCLUSIONS AND RECOMMENDATIONS}

The study revealed that in the six RPVs, small-scale paddy farmers were able to increase their income level through: selling rice instead of paddy, establishing agro-based selfemployments, processing high quality rice at cottage level, developing small/medium scale rice mills to produce high quality rice, and supplying high quality rice at a lower price to the consumers. According to this study, the members of the RPV are using the five capital sources, namely financial, physical, human, social and natural capital sources effectively for 
their own socio-economic development. Proper use of these capital sources can lead the rice processing activity to be a beneficial livelihood and income generating venture.

Further studies on an in-depth analysis of the total RPV programme would facilitate the improvement of the programme in the future and enable introducing the programme into other paddy producing rural communities in Sri Lanka. As this had shown to be a beneficial and successful programme in Anuradhpura district, special emphasis could be given to war affected northern and eastern paddy cultivating areas, as livelihood development, income generation, and women empowerment programme.

\section{REFERENCES}

Central Bank of Sri Lanka. 2012. Annual Report 2011. Central Bank of Sri Lanka, Colombo.

Curtaran, E. (2008).Sustainable local development through one town one product (OTOP): The case of Mindanao, Philippines [research note], Graduate School of Policy Science, Ritsumeikan University. 8, pp. 89-96.

Department of Census and Statistics. 2012. [online]. [Accessed on 02.05.2012]. Available at www.statistics.gov.lk/PopHouSat/Pop_Chra.asp

Gamawelagedara, W.C., Wickramasinghe, Y.M. and Dissanayake, C.A.K. 2011. Impact of rice processing villages on household income rural farmers in Anuradhapura district. The Journal of Agricultural Sciences. 6, 91-98.

Goodwin, N.R. 2003. Five kinds of capital: Useful concepts for sustainable development. Working paper no. 03-07. Global development and environment institute. Tufts university Medford MA 02155, USA. [Online]. [Accessed on 02.05.2011]. Available at http://www.ase.tufts.edu/gdae/...papers/03-07sustainabledevelopment.PDF

Institute of Post Harvest Technology. 2006. Annual Report 2005. Institute of Post Harvest Technology, Anuradhapura.

Kleih, R.A., Mohamad, M.R.B. and Ibrahim, A.A.H.C. 2009. Success factors for small rural entrepreneurs under the one-district-one-industry program in Malaysia. Contemporary Management Research, 5(2), 147-162

Kumara, S.K., Weerakkody, P.R., Epasinghe,S., and Epakanda, N.S.B. 2008. Viability of rice processing at household level. Hector Kobbekaduwa Agrarian Research and Training Institute. Colombo 07.

McConnon, J. 2008. Capital Sources for Your Business. [Online]. [Accessed on 02.05.2011]. Available at www.umaine.edu/publications/3008e/.

World Bank. 2012. [Online]. [Accessed on 24.05.2012]. Available at data.worldbank.org/indicator/SI.POV.2DAY/. 